\title{
Characterization of mechanical properties of Al-6063 deformed by ECAE
}

\begin{abstract}
The production of refined grain materials by equal channel angular extrusion (ECAE) method has been the subject of numerous research programs over the past decades. In this study, the mechanical properties of commercially Al-6063 alloy deformed through ECAE process are investigated. The extrusion is performed up to six passes at a constant speed of $30 \mathrm{~mm} / \mathrm{min}$ and a temperature of $200{ }^{\circ} \mathrm{C}$. The grain size of the material reduced from 45 to $2.8 \mu \mathrm{m}$ after six passes. The extruded specimens were tested under quasi-static, medium, and high strain rate loadings using various testing machines. The results indicated that the tensile yield stress (YS) and the ultimate tensile strength (UTS) of the extruded specimens increased significantly after five passes of the ECAE process. The major improvement occurred after the first pass. For the subsequent passes, the properties kept improving but at lower rates. It was also shown that the tensile properties of the processed specimens are not influenced by the strain rate.
\end{abstract}

Keyword: Al-6063; ECAE; Mechanical properties; Grain refinement 